\title{
LAS RECLAMACIONES SIN INFRACCIÓN EN LAS DIFERENCIAS RELATIVAS A LA PROPIEDAD INTELECTUAL EN LA OMC
}

\author{
Matthew KenNEDY*
}

SUMARIO: 1. INTRODUCCIÓN.-2. LA NATURALEZA DE LAS RECLAMACIONES SIN INFRACCIÓN Y LAS RECLAMACIONES POR OTRA SITUACIÓN.-3. LAS RECLAMACIONES SIN INFRACCIÓN EN EL MARCO DEL ADPIC.-3.1. El origen del debate.-3.2. Debate en el Consejo de los ADPIC.-3.3. El sistema de licencias obligatorias del párr. 6.-3.4. La solución de diferencias relativas a la propiedad intelectual.-4. TRATAMIENTO DE LAS RECLAMACIONES SIN INFRACCION.-4.1. Tratamiento en el ámbito de las concesiones individuales.-4.2. Tratamiento en el ámbito del ADPIC mismo.-4.2.1. Cuestión preliminar.-4.2.2. Examen de fondo.-5. CONCLUSIÓN.

\section{INTRODUCCIÓN}

1. La XI Conferencia Ministerial de la Organización Mundial del Comercio (OMC) adoptó una decisión en Buenos Aires en diciembre de 2017 sobre las reclamaciones no basadas en infracción y reclamaciones en casos en que existe otra situación en el ámbito del Acuerdo sobre los Aspectos de los Derechos de la Propiedad Intelectual relacionados con el Comercio (ADPIC) ${ }^{1}$. Fue la octava Decisión desde 2001 expresando el acuerdo de los Miembros de no presentar tales reclamaciones en el ámbito del ADPIC hasta el próximo periodo de sesiones de la Conferencia Ministerial, que tendrá lugar en Astana, Kazakstán, en 2020. Persisten las visiones opuestas entre los Miembros respecto a esta cuestión, que ya de por sí es un aspecto curioso del Derecho del comercio internacional y que se ha presentado en el contexto del Derecho de la propiedad intelectual ${ }^{2}$.

\footnotetext{
* Catedrático, Facultad de Derecho, Universidad de Negocios y Comercio Internacional (UIBE), Pekín, China y antiguo secretario del Consejo de los ADPIC de la OMC (matthew.kennedy@uibe.edu.cn).

1 Decisión Ministerial de 13 de diciembre de 2017, «Reclamaciones no basadas en una infracción y reclamaciones en casos en que existe otra situación en el ámbito de los ADPIC», WT/MIN(17)/66; WT/L/1033.

2 Consejo de los ADPIC, acta de la reunión celebrada los días 15 y 16 de octubre y 6 y 15 de noviembre de 2015, IP/C/M/80/Add.1, punto 8 del orden del día; acta de la reunión celebrada los días 19 y 20 de octubre de 2017, IP/C/M/87/Add.1, punto 7 del orden del día.
} 
2. El informe del Grupo Especial sobre Australia - Empaquetado genérico del tabaco, emitido en junio del 2018, ejemplifica el tipo de diferencia relativa a la propiedad intelectual donde se teme que las reclamaciones sin infracción pudieran plantearse en el ámbito del $\mathrm{ADPIC}^{3}$. En este asunto, Cuba, Honduras, Indonesia y la República Dominicana impugnaron una medida que afecta al uso de marcas de fábrica o de comercio en los cigarros, cigarrillos y empaquetado, alegando violaciones del ADPIC, del Acuerdo sobre Obstáculos Técnicos al Comercio (Acuerdo OTC) y del Acuerdo General sobre Aranceles Aduaneros y Comercio (GATT) de 1994. Es la primera controversia en que un grupo especial rechaza todas las reclamaciones en el ámbito del ADPIC (cabe señalar que Honduras y la República Dominicana han interpuesto recursos de apelación $)^{4}$. Las partes reclamantes tuvieron mucha dificultad en demostrar que disposiciones del ADPIC garantizaran claramente el derecho de los titulares al uso de sus marcas sobre sus productos.

3. Las partes reclamantes en Australia - Empaquetado genérico del tabaco no presentaron una reclamación alegando que, si bien el ADPIC no garantiza tal derecho, cabía legítimamente esperar el uso de las marcas en la forma en que la medida en cuestión ahora prohíbe. No lo hicieron tal vez por la Decisión Ministerial; aunque esto no lo explica del todo. Los Miembros solo acordaron en esa Decisión no presentar tales reclamaciones en el ámbito «de los ADPIC», pero esto no les impedía a las partes reclamantes alegar que la medida australiana anulaba o menoscababa ventaja legítimamente esperada de las concesiones arancelarias para cigarros y cigarrillos consolidadas en el marco del GATT de 1994. Se limitaron, en cambio, a presentar reclamaciones por supuestas violaciones.

4. La relación entre el GATT de 1994 y el ADPIC es la clave para entender el alcance de las reclamaciones sin infracción en las diferencias relativas a la propiedad intelectual en la OMC. Al final de la Ronda Uruguay, un malentendido con respecto a la aplicación acumulativa de esos dos acuerdos llevó a la modificación del art. 64 del ADPIC, agregándole los párrs. 2 y 3. Desarrollos posteriores en la solución de diferencias en la OMC (confirmados en los mismos informes del Grupo Especial en Australia - Empaquetado genérico del tabaco) aclararon esa relación de manera suficiente para que un grupo especial futuro dictamine sobre tales reclamaciones, incluso en circunstancias en que la Decisión Ministerial sobre el tema haya vencido.

5. Los temores con respecto a las reclamaciones sin infracción se han incrementado con el surgimiento en paralelo de demandas de protección

\footnotetext{
3 Informes del Grupo Especial, Australia - Determinadas medidas relativas a las marcas de fábrica o de comercio, indicaciones geográficas y otras prescripciones de empaquetado genérico aplicables a los productos de tabaco y al empaquetado de esos productos ( Australia - Empaquetado genérico de tabaco»), WT/DS435/R/WT/DS441/R/WT/DS458/R / WT/DS467/R.

4 Los informes del Grupo Especial con respecto a las reclamaciones presentadas por Cuba e Indonesia se adoptaron en la reunión del OSD del 27 de agosto de 2018: véanse WT/DS458/22/Corr.1 y WT/ DS467/23. Previamente, Honduras y la República Dominicana presentaron apelaciones contra ciertas constataciones del Grupo Especial: véanse WT/DS435/23 y WT/DS441/23.
} 
de las expectativas legítimas de los inversores en relación a sus derechos de propiedad intelectual en el ámbito de tratados bilaterales de inversión ${ }^{5}$. No obstante, el alcance de las reclamaciones sin infracción en un asunto de propiedad intelectual en la OMC puede ser resuelto sin una reflexión sobre los estándares aplicables en el Derecho internacional de inversiones.

6. El presente artículo comienza presentando las reclamaciones sin infracción y reclamaciones por otra situación y explica el malentendido que llevó a introducir esta cuestión en el ADPIC. A continuación, se consideran los desarrollos pertinentes en los debates del Consejo de los ADPIC, la enmienda al ADPIC y también la solución de diferencias. El artículo desarrolla un marco interpretativo y lo aplica a las reclamaciones sin infracción que se podrían plantear en una diferencia relativa a la propiedad intelectual, primero en el ámbito de las concesiones arancelarias consolidadas en el marco del GATT de 1994 y luego en el ámbito del ADPIC.

\section{LA NATURALEZA DE LAS RECLAMACIONES SIN INFRACCIÓN Y LAS RECLAMACIONES POR OTRA SITUACIÓN}

7. La gran mayoría de las reclamaciones en el sistema de solución de diferencias de la OMC son basadas en alegaciones de infracciones, pero también se prevén reclamaciones sin infracción y reclamaciones por otra situación. Estos tres tipos de reclamación figuran en el art. XXIII:1 del GATT de 1994 que es desarrollado y modificado por el Entendimiento relativo a las normas y procedimientos por los que se rige la solución de diferencias (ESD). El art. XXIII del GATT de 1994 y el ESD son aplicables en el ámbito del ADPIC ${ }^{6}$.

8. Las reclamaciones sin infracción alegan que la aplicación de una medida de otro Miembro causó daño, aunque la medida no infrinja una concesión u obligación. Es un aspecto raro del Derecho del comercio internacional más antiguo que el propio GATT de 1947. La reclamación sin infracción ya se incluía en acuerdos comerciales bilaterales antes de la Segunda Guerra Mundial con miras a prevenir que las partes socavaran los resultados de las negociaciones ${ }^{7}$. En esa época, las negociaciones comerciales se enfocaban en la reducción de los aranceles aduaneros; las obligaciones generales en los acuerdos eran relativamente escasas, lo cual no era suficiente para impedir la

\footnotetext{
5 Véanse Philip Morris Brands sàrl et al v. República Oriental del Uruguay, caso CIADI núm. ARB/10/7, Laudo, 8 de julio de 2016; Eli Lilly and Company v. Government of Canada, caso CIADI núm. UNCT/14/2, Laudo definitivo, 16 de marzo de 2017. Véase, también, Philip Morris Asia Limited v. The Commonwealth of Australia, caso CPA núm. 2012-12, Laudo sobre competencia y admisibilidad, 17 de diciembre de 2015.

6 ADPIC, art. 64.1.

7 Cottier, T. y NadaKavukaren Schefer, K., "Non-Violation Complaints in GATT/WTO Dispute Settlement: Past, Present and Future», en Petersmann, E.-U. (ed.), International Trade Law and the GATT/WTO Legal System, La Haya, Kluwer Law International, 1997, pp. 145-183, esp. pp. 149-153; CHo, S., "GATT Non-Violation Issues in the WTO Framework: Are They the Achilles' Heel of the Dispute Settlement Process?», Harvard International Law Journal, vol. 39, 1998, pp. 311-355, esp. pp. 314-315.
} 
aplicación de medidas de mala fe. Los resultados de las negociaciones arancelarias se basaban en un balance general entre las concesiones ofrecidas por cada parte para distintos productos en su mercado respectivo, enumeradas en su lista individual. Dado que tal balance requería una comparación entre manzanas y naranjas (literalmente), se evaluaba en términos del acceso a los mercados o de «la ventaja» que cabía legítimamente esperar de cada concesión. Si una parte aplicaba una nueva medida de manera inesperada tras el fin de la negociación, defraudando las expectativas legítimas de la otra parte con respecto a esa ventaja, esta tenía motivo para reclamar resarcimiento, aunque la medida estuviera conforme a la letra de las concesiones y obligaciones del acuerdo en cuestión. Ese derecho a reclamar también se incluyó en el GATT de $1947^{8}$.

9. El ejemplo clásico de una reclamación sin infracción era un subsidio otorgado a los productores o consumidores de un producto tras una negociación arancelaria que compensaba sistemáticamente el impacto de la reducción arancelaria para el mismo producto o un producto competidor. El país exportador esperaba legítimamente que la reducción arancelaria negociada llevara a una mejora del acceso al mercado del país importador, pero al final de cuentas se veía estafado por el subsidio que socavaba el balance entre las concesiones acordadas por los países de importación y de exportación, sin infringir ninguna obligación en el GATT ${ }^{9}$. Una reclamación sin infracción concedía un derecho de resarcimiento por este tipo de conducta desleal.

10. Hoy la OMC administra muchos más acuerdos que el GATT. Cuantas más obligaciones generales haya, más infracciones puede haber; por lo que habrá menos necesidad de recurrir a las reclamaciones sin infracción para proteger el valor de concesiones individuales. No importa en qué acuerdo multilateral de la OMC figuran las obligaciones porque todos los acuerdos se negociaron dentro de un compromiso único. Por otra parte, a diferencia de ciertos acuerdos comerciales regionales, los acuerdos de la OMC no contienen una disposición que contemple de manera explícita reclamaciones sin infracción de una obligación general ${ }^{10}$.

11. Las reclamaciones sin infracción podrían ser útiles cuando otro Miembro encuentra formas de socavar el valor de sus concesiones o compromisos individuales. Aunque los Miembros pueden intentar eludir también el cumplimiento de las obligaciones generales de los acuerdos, ningún Miembro ha iniciado hasta ahora una reclamación sin infracción sobre esta

\footnotetext{
${ }^{8}$ Véase el Informe del Grupo Especial del GATT, CEE - Primas y subvenciones abonadas a los elaboradores y a los productores de semillas oleaginosas y proteínas conexas destinadas a la alimentación animal («CEE - Oleaginosas I»), adoptado el 25 de enero de 1990, IBDD 37S/86, párr. 144, reproducido en el Informe del Órgano de Apelación, Comunidades Europeas - Medidas que afectan al amianto y a los productos que contienen amianto («CE - Amianto»), WT/DS135/AB/R, párr. 186.

9 Véase el Informe del Grupo de Trabajo del GATT, Australia - Subvenciones al sulfato amónico, GATT/CP.4/39, adoptado el 3 de abril de 1950, IBDD II/188.

10 Véase, por ejemplo, el Tratado de Libre Comercio de América del Norte («TLCAN»), art. 2004 y anexo 2004, párr. 1(d). Cfr. Acuerdo sobre Subvenciones y Medidas Compensatorias, art. 5(b).
} 
base. Las obligaciones generales se aplican de manera «horizontal» a todos los Miembros y es difícil concebir que cupiera legítimamente esperar un derecho de resarcimiento cuando las obligaciones mismas ya se cumplen. Las soluciones al problema de elusión de las obligaciones generales son disposiciones expresas sobre la prevención de elusión, la interpretación de buena fe de los tratados y, de ser necesario, una modificación del acuerdo en una nueva negociación.

12. El Acuerdo General sobre el Comercio de Servicios (AGCS) adopta el análisis arriba expuesto en el sentido de que dispone que las reclamaciones sin infracción se pueden iniciar únicamente en virtud de compromisos específicos, o sea, individuales ${ }^{11}$. El AGCS es un acuerdo basado en el modelo del GATT que se adaptó al comercio de servicios. Compromisos específicos con respecto al comercio de servicios, del mismo modo que las concesiones arancelarias en el caso del comercio de mercancías, se ofrecen por cada Miembro individualmente hasta obtener un balance general. Lo mismo ocurre con respecto a las entidades cubiertas por cada parte en el marco del Acuerdo (plurilateral) sobre Contratación Pública (ACP) ${ }^{12}$.

13. Cabe señalar que es muy difícil prevalecer con una reclamación sin infracción y que la sanción correspondiente es débil. El Órgano de Apelación confirmó que este tipo de reclamación debe ser objeto de un enfoque prudente y seguir siendo una acción excepcional ${ }^{13}$. El reclamante debe presentar una justificación detallada porque no goza de la presunción de anulación y menoscabo de sus intereses al no haber incumplimiento de obligaciones ${ }^{14}$. En los pocos casos del GATT en que estas reclamaciones tuvieron éxito, el impacto de la medida fue muy importante; en el sentido de que anulaba completamente, o menoscababa seriamente y no de a poco, el acceso al mercado esperado. La sanción por una reclamación sin infracción exitosa es un arreglo llamado "ajuste mutuamente satisfactorio» ${ }^{15}$, el cual conlleva una negociación sobre compensación.

14. Las reclamaciones "por otra situación» (el tercer supuesto) son inauditas desde el establecimiento de la OMC. Esas reclamaciones impugnan la anulación y menoscabo de una ventaja del acuerdo debido a «la existencia de otra situación» no abarcada por las reclamaciones con infracción o la aplicación de una medida sin infracción. Unas pocas reclamaciones por otra situación se mencionaron al pasar en el GATT. Este tipo de reclamación es aplicable también a la mayoría de los acuerdos de la OMC, al menos en teoría. Ningún Miembro ha presentado hasta ahora tal reclamación en el ámbito de un acuerdo de la OMC, pero si sucediera algún día, un eventual

11 AGCS, art. XXIII:3.

12 Acuerdo sobre Contratación Pública, art. XXII:2. Véase, por ejemplo, el Informe del Grupo Especial, Corea - Medidas que afectan a la contratación pública ( Corea - Contratación pública»), WT/ DS163/R.

13 Informe del Órgano de Apelación, CE - Amianto, párr. 186.

14 ESD, art. 3.8.

15 ESD, art. 26.1(b). 
grupo especial tendría que abordarla en un informe separado. Tal informe se podría adoptar únicamente mediante consenso positivo que constituye un remanente del antiguo procedimiento de adopción de decisiones del GATT ${ }^{16}$. En efecto, cada Miembro podría vetar la adopción de un informe con respecto a ese tipo de reclamación. La sanción correspondiente ni siquiera está prevista.

\section{LAS RECLAMACIONES SIN INFRACCIÓN EN EL MARCO DEL ADPIC}

15. Existe un debate sobre el alcance de las reclamaciones sin infracción en el marco del ADPIC desde las negociaciones previas al establecimiento de la OMC. El debate de esta cuestión en el Consejo de los ADPIC ha evolucionado poco, con un solo resultado definitivo. Para seguir adelante, sería importante recordar el origen del debate y constatar acontecimientos en la solución de diferencias en los últimos años.

\subsection{El origen del debate}

16. El debate actual sobre las reclamaciones sin infracción y las reclamaciones por otra situación en el ámbito del ADPIC empezó cuando el proyecto de acuerdo en esta materia se integró a los proyectos del ESD y del acuerdo paraguas de la OMC durante la Ronda Uruguay ${ }^{17}$. En ese momento, el único proyecto de acuerdo que disponía algo especial con respecto a esos dos tipos de reclamaciones era el AGCS. Fue recién después de la inclusión del ADPIC en un anexo separado, al igual que el AGCS, que una delegación planteó la preocupación de que el ADPIC no tuviera una disposición especial para esos tipos de reclamaciones. Sin embargo, la ubicación del ADPIC en un anexo separado se hizo por las sanciones cruzadas y temas de administración y no por las reclamaciones sin infracción ${ }^{18}$.

17. El proyecto del ADPIC, que ya estaba acordado de manera informal desde diciembre de 1991, solo contenía la disposición estándar del GATT con respecto a la solución de diferencias. La razón por la cual se siguió discutiendo esta disposición se señaló en el proyecto exhaustivo conocido como el «Borrador Dunkel» (Dunkel draft) en los siguientes términos:

«Esta disposición quizá haya de revisarse a la luz de los resultados de los trabajos relativos al establecimiento de un Entendimiento relativo a un Sistema

${ }^{16} \mathrm{ESD}$, art. 26.2.

17 El grupo de negociaciones sobre los ADPIC ya había discutido las reclamaciones sin infracción, pero únicamente porque el art. 8 del proyecto de Acuerdo contenía una defensa respecto a este tipo de reclamación: véase OMC, «Las reclamaciones sin infracción de disposiciones y el Acuerdo sobre los ADPIC», Nota de la Secretaría, 28 de enero de 1999, IP/C/W/124, párr. 13.

18 KENNEDY, M., WTO Dispute Settlement and the TRIPS Agreement: Applying intellectual property standards in a trade law framework, Cambridge, Cambridge University Press, 2016, pp. 29-30. 
Integrado de Solución de Diferencias en el marco del Acuerdo por el que se establece la Organización [Mundial] del Comercio» ${ }^{19}$.

18. El aspecto crucial de la integración del ADPIC en el ESD y en el Acuerdo OMC fue las sanciones cruzadas ${ }^{20}$. Las sanciones comerciales constituyeron una amenaza frecuente en los asuntos de propiedad intelectual durante las negociaciones del ADPIC. En 1988, los Estados Unidos aplicaron derechos arancelarios del 100 por 100 ad valorem sobre mercancías brasileñas por un valor de 39 millones de dólares por la falta de protección de fármacos mediante patentes en el país sudamericano ${ }^{21}$. Los proponentes del ADPIC querían integrarlo en el ESD con miras a obtener una autorización multilateral de sanciones para este tipo de medida ${ }^{22}$. Los países en desarrollo querían que en caso de que el ADPIC se integrara en la OMC, que el ESD restringiera la aplicación de sanciones sobre las mercancías en diferencias con respecto a la propiedad intelectual y permitiera las sanciones sobre la propiedad intelectual en diferencias con respecto a las mercancías. También querían asegurar que la OMC mantuviera separados los debates sobre la propiedad intelectual y el comercio de las mercancías ${ }^{23}$. El resultado fue el establecimiento del ADPIC como otro «acuerdo abarcado» por el ESD ${ }^{24}$ pero en un anexo separado del Acuerdo $\mathrm{OMC}^{25}$ con principios y procedimientos en el ESD para limitar las sanciones cruzadas entre los anexos ${ }^{26}$ y un Consejo separado para supervisar el funcionamiento del acuerdo ${ }^{27}$. Los anexos separados reflejan el funcionamiento de las disposiciones sobre sanciones cruzadas y administración, nada más.

19. Canadá sostuvo que la separación del ADPIC en un anexo propio desvirtuaba la disposición modelo del GATT sobre la solución de diferencias ${ }^{28}$. Esa disposición se refiere al art. XXIII del GATT de 1994 que prevé no solo

19 «Acta Final en que se incorporan los resultados de la Ronda Uruguay de negociaciones comerciales multilaterales», 20 de diciembre de 1991, MTN.TNC/W/FA, p. 89, n. 1. Cfr. Sección T, «Elementos de un sistema integrado de solución de diferencias» y Anexo IV «Acuerdo por el que se establece la Organización Multilateral del Comercio», Anexo 1.

${ }^{20}$ La organización internacional en la cual el ADPIC se implementaría, una cuestión estrechamente vinculada con los procedimientos de solución de diferencias, quedó reservada en la Decisión de revisión intermedia de la Ronda Uruguay, 11 de abril de 1989, MTN.TNC/9, p. 9, y el proyecto de Bruselas, 3 de diciembre de 1990, MTN.TNC/W/35/ Rev.1, p. 2, n. 1; p. 193, n. 1; p. 229.

21 Presidente de Estados Unidos de América, Proclamación 5885, 20 de octubre de 1988, 53 Fed. Reg. 41551.

22 «Sugerencias de los Estados Unidos para alcanzar el objetivo de la negociación», 20 de octubre de 1987, MTN.GNG/NG11/W/14, p. 4. Véase, también, «Directrices y objetivos propuestos por la Comunidad Europea para las negociaciones sobre los aspectos de las normas sustantivas de los derechos de propiedad intelectual relacionados con el comercio», 7 de julio de 1988, MTN.GNG/NG11/W/26, p. 13.

${ }^{23}$ Amorim, C., antiguo Director General de Asuntos Económicos, Cancillería brasileña, carta al autor del 18 de septiembre de 2014; Stoler, A. L., "The WTO Dispute Settlement Process: Did the Negotiators Get What They Wanted?», World Trade Review, vol. 3, 2004, pp. 99-118, esp. p. 105.

24 ESD, art. 1 y Apéndice 1.

25 Acuerdo OMC, Lista de Anexos.

26 ESD, art. 22.3(f)(iii) y (g)(iii).

27 Acuerdo OMC, art. IV:5.

28 STEGER, D., antigua negociadora del Canadá sobre instituciones y solución de diferencias en la Ronda Uruguay, correo al autor de fecha 10 de julio de 2014. 
las reclamaciones basadas en supuestas infracciones sino también reclamaciones sin infracción y reclamaciones por otra situación. Teniendo en cuenta que no hay listas de compromisos individuales en el mismo anexo que el ADPIC, se temió que esa disposición se pudiera interpretar de forma que permitiera reclamaciones sin infracción en virtud de ventajas derivadas de las obligaciones mismas del propio acuerdo ${ }^{29}$. Al parecer, ese temor derivaba de una comparación con el AGCS que también figura en un anexo separado, aunque solo permite las reclamaciones sin infracción vinculadas a sus propias listas de compromisos individuales ${ }^{30}$.

20. Sin embargo, no hay motivo para leer el ADPIC en aislamiento de esa manera. Los anexos no fragmentan la estructura de la OMC, tal como lo hicieron los antiguos códigos del GATT. La integración del mecanismo de solución de diferencias en el ESD permite examinar en la misma diferencia distintos acuerdos abarcados en diversos anexos. Las concesiones arancelarias dispuestas en las listas de mercancías de un Miembro individual siguen aplicándose, por más que el GATT de 1994, el Acuerdo OTC, el Acuerdo sobre la Aplicación de Medidas Sanitarias y Fitosanitarias (MSF), el ADPIC y otras obligaciones puedan afectar la comercialización de los mismos productos ${ }^{31}$. No importa el anexo en el que figura cada obligación y concesión.

21. Por tanto, una reclamación sin infracción puede impugnar la aplicación de medidas que afectan mercancías protegidas mediante la propiedad intelectual. La reclamación sin infracción puede basarse en la ventaja de una concesión arancelaria pertinente. El hecho de que las obligaciones del ADPIC y las concesiones arancelarias consolidadas en el marco del GATT de 1994 figuran en anexos separados del Acuerdo OMC no tiene ninguna relevancia respecto a la disponibilidad de las reclamaciones sin infracción.

22. Las reclamaciones por otra situación en el ámbito del ADPIC se incorporaron en el mismo debate que las reclamaciones sin infracción, tal como se hizo en otras áreas de la Ronda Uruguay. Ambos tipos de reclamación se abordan en el art. 26 del ESD. La disposición especial en el AGCS que restringe las reclamaciones sin infracción también excluye las reclamaciones por otra situación. El debate sobre los tipos de reclamación en el ámbito del ADPIC brindó también una oportunidad de eliminar de este acuerdo ese raro derecho a reclamar.

23. No hubo consenso para excluir ni uno ni otro tipo de reclamaciones del ámbito del ADPIC. La solución de compromiso agregada como los párrs. 2 y 3 del art. 64 del ADPIC en 1993 fue una moratoria de cinco años

29 Además, el Proyecto de elementos de un mecanismo integrado de solución de diferencias incluía una disposición en el sentido que «[c]uando determinados acuerdos contengan disposiciones relacionadas con diferencias surgidas en casos en los que no exista infracción, se aplicará el siguiente procedimiento», Borrador Dunkel, supra nota 19, p. T.4. Cfr. art. 26.1 en el texto final del ESD, infra párr. 44.

30 Canadá venía de negociar el TLCAN donde se habían acordado disposiciones sobre reclamaciones sin infracción y propiedad intelectual. Véase supra nota 10.

31 Roessler, F., "The Concept of Nullification and Impairment in the Legal System of the World Trade Organization» en Petersmann, E.-U. (ed.), op. cit., nota 7, pp. 123-142, esp. p. 136. 
con respecto a la iniciación de esos tipos de reclamaciones y una instrucción a que el Consejo de los ADPIC examinara la cuestión y presentara sus recomendaciones ${ }^{32}$.

\subsection{Debate en el Consejo de los ADPIC}

24. En el Consejo de los ADPIC el debate sobre esta cuestión se encuentra en una situación de punto muerto desde hace mucho tiempo ${ }^{33}$. Los Miembros han debatido la impugnación potencial de medidas comerciales y regulatorias que pudieran afectar productos protegidos mediante la propiedad intelectual y también las mismas medidas de propiedad intelectual. Unos ejemplos típicos serían la reglamentación de precios de fármacos patenta$\operatorname{dos}^{34}$ y las cuotas de difusión de películas protegidas mediante el derecho de autor. Muchos Miembros temen que, de permitirse las reclamaciones sin infracción y reclamaciones por otra situación en el ámbito del ADPIC, se alteraría el equilibrio de derechos y obligaciones en el Acuerdo y se socavaría la autoridad regulatoria de los Miembros ${ }^{35}$. Los Estados Unidos (que han iniciado más diferencias en el ámbito del ADPIC que cualquier otro Miembro) y Suiza mantienen que esos tipos de reclamaciones podrían prevenir la elusión de obligaciones ${ }^{36}$.

25. Se trata de un debate bastante forzado, ya que considera al ADPIC en aislamiento mientras el mecanismo de solución de diferencias de la OMC es integrado. El mandato original para el debate se limitó a reclamaciones que se plantearan de conformidad con el ADPIC ${ }^{37}$. Aunque el debate incluyó un examen de la jurisprudencia del GATT/OMC, como así también de la coherencia entre los diferentes acuerdos de la OMC, las posiciones principales se endurecieron en una perspectiva de «todo o nada» respecto a las reclamaciones sin infracción únicamente en el ámbito del ADPIC. Sin embargo, esta

32 Bello, J. H., «Some Practical Observations about WTO Settlement of Intellectual Property Disputes», Virginia Journal of International Law, vol. 37, 1997, pp. 357-367, esp. p. 365.

${ }_{33}$ El Consejo de los ADPIC no logró un consenso al respecto antes de 2000. Por tal motivo, las Decisiones Ministeriales han reiterado la instrucción de presentar recomendaciones, pero el Consejo ha fracasado cada vez en su intento al no lograr el consenso necesario.

${ }^{34}$ Véase Correa, C. M., Trade Related Aspects of Intellectual Property Rights: A Commentary on the TRIPS Agreement, Oxford Commentaries on International Law, Oxford, Oxford University Press, 2007, pp. 488-489.

35 Comunicación de la Argentina, Bolivia, Brasil, China, Colombia, Cuba, Ecuador, Egipto, Federación Rusa, Grupo Africano, Grupo de los PMA, India, Indonesia, Kenia, República Kirguiza, Malasia, Pakistán, Perú, Sri Lanka y Venezuela, «Anulación o Menoscabo sin Infracción de Disposiciones y Otras Situaciones en el Marco del Acuerdo sobre los ADPIC», IP/C/W/385/Rev.1, 22 de mayo de 2015, y adenda.

${ }^{36}$ Comunicación de los Estados Unidos, «Reclamaciones no basadas en una infracción en el ámbito del Acuerdo ADPIC», IP/C/W/599, 10 de junio de 2014. Véase, también, Emergency Committee for American Trade, National Association of Manufacturers, National Foreign Trade Council y US Chamber of Commerce carta de fecha 22 de noviembre de 2011 al Sr. Ron Kirk, Representante Comercial de Estados Unidos; Business Europe, carta de fecha 8 de diciembre de 2011 al Sr. Karel de Gucht, Comisario Europeo para el Comercio.

37 ADPIC, art. 64.3. 
es una cuestión a ser resuelta en el marco del ESD, teniendo en cuenta que es un mecanismo que se aplica a todos los acuerdos abarcados. Las reclamaciones se presentan ante los grupos especiales invocando varios acuerdos en las mismas controversias, lo cual también es cada vez más frecuente en las diferencias relativas a la propiedad intelectual. Sin embargo, eso no se ha visto reflejado en el debate en el Consejo de los ADPIC. El Consejo no ha tomado en consideración el papel que desempeñan las reclamaciones sin infracción en el ámbito de otros acuerdos de la OMC en las diferencias relativas a la propiedad intelectual en su conjunto, lo cual podría poner la discusión en perspectiva.

26. Tampoco el debate ha sido siempre preciso. Se ha señalado erróneamente que «en tres informes de grupos especiales del GATT se habían examinado [...] reclamaciones sin infracción basadas en obligaciones generales y no en concesiones arancelarias específicas y se había constatado que el párr. 1.b) del art. XXIII del GATT no se aplicaba únicamente a las ventajas arancelarias» ${ }^{38}$. En realidad, un solo Grupo Especial del GATT (CE - Cítricos) examinó una reclamación de ese índole, en circunstancias sumamente dudosas, por las cuales su informe nunca llegó a adoptarse ${ }^{39}$. Además, se ha señalado que el alcance de las reclamaciones sin infracción no se limita a las concesiones arancelarias, cuando en todos los asuntos de la OMC se ha limitado al contexto de concesiones individuales de algún tipo, lo que el ADPIC no contiene ${ }^{40}$.

27. La naturaleza única de las obligaciones del ADPIC en el sistema de la OMC se menciona con frecuencia en este debate, pero este argumento es irrelevante. Las reclamaciones sin infracción son un aspecto del Derecho del comercio internacional, no del Derecho de la propiedad intelectual ${ }^{41}$. La naturaleza positiva de la mayoría de las obligaciones del ADPIC (que disponen lo que los Miembros deben hacer) se puede distinguir de la naturaleza negativa de las obligaciones que tienden a la liberalización del comercio internacional (que disponen lo que los Miembros no deben hacer). Por tanto, el punto decisivo no es que el ADPIC contiene obligaciones «únicas», sino más bien que el mismo solo contiene obligaciones generales, sin compromisos individuales ${ }^{42}$.

28. Es irónico que la naturaleza única de las obligaciones de la propiedad intelectual se mencione en relación con este aspecto tan limitado del

$38 \mathrm{OMC}$, «Reclamaciones en casos en que no existe infracción y reclamaciones en que existe otra situación», Nota recapitulativa de la Secretaría, IP/C/W/349/Rev.2, 19 de octubre de 2012, párr. 12.

39 El propio Grupo Especial fue el primero en sugerir una reclamación sin infracción: véase Informe del Grupo Especial del GATT, Comunidad Europea - Trato arancelario concedido a las importaciones de productos cítricos procedentes de algunos países de la región del Mediterráneo («CE - Cítricos»), L/5576, 7 de febrero de 1985, no adoptado. La nota recapitulativa de la Secretaría de la OMC (supra nota 38) enumera otros tres casos, pero el primero es un error, en el segundo no se citó una obligación específica en ese respecto y en el tercero no se presentó una justificación.

$40 \mathrm{IP} / \mathrm{C} / \mathrm{W} / 599$ (supra nota 36), párrs. 3.9-3.11.

${ }^{41}$ Cfr. Evans, G. E., "A Preliminary Excursion into TRIPS and Non-Violation Complaints», Journal of World Intellectual Property, vol. 3, 2000, núm. 6, pp. 867-888, esp. pp. 873-874.

${ }^{42}$ Roessler, F., op. cit., nota 31, pp. 137-138. 
Derecho del comercio internacional — donde no importa- cuando se ignora en relación con tantos otros aspectos de la solución de diferencias —donde sí podría importar mucho-. Esos aspectos abarcan los términos de referencia, la carga de la prueba, la experiencia especializada de los integrantes del grupo especial, el examen del Derecho interno, la relación a convenios externos y la forma de las contramedidas ${ }^{43}$. El Consejo de los ADPIC no se involucra en esas cuestiones relativas a la aplicación del ESD al ADPIC, sino que deja a los grupos especiales resolverlas.

29. El estancamiento del debate en el Consejo de los ADPIC llevó a la serie de Decisiones Ministeriales que postergan una acción definitiva, lo cual podría ser contraproducente. Decisiones acordando no presentar esos tipos de reclamaciones pueden alentar a las partes a hacer inferencias a contrario que, de ser presentadas, las mismas podrían ser válidas.

\subsection{El sistema de licencias obligatorias del párr. 6}

30. Una sola acción definitiva se tomó con respecto a este tema, dentro de un ámbito muy limitado. De acuerdo al párr. 6 de la «Declaración de Doha relativa al Acuerdo sobre los ADPIC y la Salud Publica» ${ }^{44}$, ciertos requisitos del ADPIC no se aplican a las licencias obligatorias para exportar medicamentos a países cuyas capacidades de fabricación en el sector farmacéutico son insuficientes o inexistentes (el llamado «sistema del párr. 6»). Este sistema se estableció primero mediante una exención adoptada en $2003^{45}$ y se incorporó luego en una enmienda al ADPIC adoptada en $2005^{46}$, que entró en vigor en $2017^{47}$. El nuevo art. 31 bis del ADPIC dispone explícitamente lo siguiente:

«4. Los Miembros no impugnarán al amparo de los apdos. b) y c) del párr. 1 del art. XXIII del GATT de 1994 ninguna medida adoptada de conformidad con las disposiciones del presente artículo y del Anexo del presente Acuerdo» ${ }^{48}$.

31. Esta disposición excluye de manera definitiva reclamaciones sin infracción y por otra situación. Las medidas a las que se aplica se limitan a las que sean adoptadas de conformidad con el sistema del párr. 6, pero los acuerdos a los que se aplica no están limitados al ADPIC. Por ende, la disposición pretende excluir esos tipos de reclamaciones presentadas en cualquier ámbito, incluso el de las concesiones arancelarias para los fármacos consolidadas en el marco del art. II del GATT de $1994^{49}$.

\footnotetext{
43 KenNedy, M., op. cit., nota 18, caps. 3, 4 y 6.

$44 \mathrm{WT} / \mathrm{MIN}(01) / \mathrm{DEC} / 2$.

45 Decisión del Consejo General de 30 de agosto de 2003, «Aplicación del párrafo 6 de la Declaración de Doha relativa al Acuerdo sobre los ADPIC y la Salud Pública», WT/L/540 y Corr. 1.

46 «Protocolo por el que se enmienda el Acuerdo sobre los ADPIC», WT/L/641.

47 Notificación de entrada en vigor, WT/Let/1236.

48 ADPIC, art. 31 bis(4), que surte efecto solo para los Miembros que han aceptado la enmienda.

49 Véase, también, la decisión de exención de 2003, infra nota 45, párr. 10.
} 


\subsection{La solución de diferencias relativas a la propiedad intelectual}

32. Mientras el debate continúa en el Consejo de los ADPIC, el mecanismo de solución de diferencias logró aclarar la relación entre el ADPIC y los demás acuerdos en otros anexos del Acuerdo OMC. Queda claro que el ADPIC se aplica de manera acumulativa con el GATT de 1994 y los demás acuerdos de la OMC, tal como constataron los informes del Grupo Especial en $C E$ - Marcas de fábrica o comercio e indicaciones geográficas en $2005^{50}$. Los informes del Grupo Especial en Australia - Empaquetado genérico de tabaco en 2018 subrayó que la aplicación concurrente de esos acuerdos entraña la posibilidad de examinar la misma medida en el marco de todas las disposiciones aplicables ${ }^{51}$. Las listas de concesiones relativas al comercio de mercancías, que forman parte integrante de la primera parte del GATT de 1994, se pueden aplicar a la misma materia que las obligaciones del ADPIC.

33. Esto tiene un impacto sobre las reclamaciones sin infracción. La aplicación acumulativa del GATT de 1994 y el ADPIC indica que las reclamaciones en el ámbito de las concesiones arancelarias se pueden presentar cuando se impugnan medidas de propiedad intelectual $\mathrm{u}$ otras medidas que afectan el comercio de mercancías protegidas mediante propiedad intelectual.

34. Curiosamente, la única referencia directa a reclamaciones sin infracción en una diferencia de la OMC relativa a la propiedad intelectual no resulta relevante. El informe del Órgano de Apelación en India - Patentes (EEUU) en 1997, discutía la posibilidad de esas reclamaciones en el ámbito del ADPIC después del fin de la moratoria del art. $64.2^{52}$. Pero en este asunto no se presentó una reclamación sin infracción. Cabría observar que la Secretaría del Órgano de Apelación en ese momento estaba encabezada por la misma persona que había propuesto la exclusión de tales reclamaciones en el ámbito de dicho acuerdo durante la Ronda Uruguay después de la ubicación del ADPIC en un anexo separado ${ }^{53}$.

\section{TRATAMIENTO DE LAS RECLAMACIONES SIN INFRACCIÓN}

35. El tratamiento de una reclamación sin infracción en un asunto de propiedad intelectual variaría si se presentara en el ámbito de concesiones individuales o del propio ADPIC ${ }^{54}$.

50 Informes del Grupo Especial, Comunidades Europeas - Medidas relacionadas con la protección de las marcas de fábrica o de comercio y las indicaciones geográficas en el caso de los productos agrícolas y los productos alimenticios («CE - Marcas de fábrica o comercio e indicaciones geográficas») (EEUU), WT/ DS174/R, párr. 7.208; y (Australia), WT/DS290/R, párr. 7.244.

51 Informes del Grupo Especial, Australia - Empaquetado genérico de tabaco, párr. 7.83 .

52 El informe del Órgano de Apelación, India - Protección mediante patente para los productos farmacéuticos y los productos químicos para la agricultura, WT/DS50/AB/R, reproduce integralmente la moratoria en el art. 64.2 del ADPIC y recuerda el mandato en el art. 64.3. Véanse párrs. 33-48, en particular párr. 42.

53 Véase supra párr. 19.

${ }^{54}$ KenNedy, M., op. cit., nota 18, cap. 7. 


\subsection{Tratamiento en el ámbito de las concesiones individuales}

36. La Decisión Ministerial solo abarca las reclamaciones sin infracción o las reclamaciones por otra situación en el ámbito del ADPIC. Sin embargo, ello no impide a los Miembros iniciar reclamaciones sin infracción en diferencias que involucran otros acuerdos de la OMC relativos a la reglamentación nacional, basándolas en concesiones arancelarias. Esas reclamaciones dan una idea de lo que ya es posible aún en disputas sobre propiedad intelectual. De todas maneras, cabe recordar que ninguna reclamación sin infracción tuvo éxito desde el establecimiento de la $\mathrm{OMC}^{55}$.

37. Por ejemplo, algunos Miembros, entre otros México, en los últimos años iniciaron reclamaciones sin infracción para cuestionar prescripciones en materia de etiquetado y de comercialización de productos, basándolas en concesiones arancelarias, independientemente del acuerdo sobre las mercancías en que basaron las reclamaciones por infracción. En EEUU - EPO, México y Canadá impugnaron ciertas prescripciones de etiquetado indicativas del país de origen de productos de la carne. Todas las reclamaciones por infracción se basaron en las obligaciones del Acuerdo OTC y el GATT de 1994 mientras que las reclamaciones sin infracción se basaron en las concesiones arancelarias de Estados Unidos para el ganado bovino y porcino ${ }^{56}$. Asimismo, en CE - Productos derivados de las focas en 2013, las reclamaciones por infracción se basaron en obligaciones del Acuerdo OTC y el GATT de 1994, mientras que las reclamaciones sin infracción se basaron en las concesiones arancelarias de la $\mathrm{CE}$ para los productos derivados de las focas ${ }^{57}$. Esos grupos especiales no examinaron en detalle las reclamaciones sin infracción porque estimaron que sus conclusiones respecto a las infracciones eran suficientes para resolver las diferencias.

38. Las reclamaciones sin infracción se podrían presentar también en asuntos que impugnan medidas de propiedad intelectual, incluso cuando algunas o todas las reclamaciones de violación se basan en supuestas infracciones de las obligaciones del ADPIC. Por ejemplo, en Australia - Empaquetado genérico de tabaco, Cuba, Honduras, Indonesia y la República Dominicana impugnaron una medida relativa a las marcas de fábrica o de comercio que afecta el empaquetado para la venta al por menor y el aspecto de los productos de tabaco. Las reclamaciones por infracción se basaron en obligaciones

55 La reclamación sin infracción más importante de la época OMC [Japón - Medidas que afectan a las películas y el papel fotográficos de consumo ("Japón - Películas»)] terminó con una derrota en 1998. Otras reclamaciones sin infracción (CE - Amianto y Corea - Contratación pública) fracasaron en 2000.

56 Informes del Grupo Especial, Estados Unidos - Determinadas prescripciones en materia de etiquetado indicativo del país de origen («EEUU - EPO»), WT/DS384/R / WT/DS386/R, párrs. 7.888-7.907; Informes del Grupo Especial, EEUU - EPO (art. 21.5 - Canadá y México), WT/DS384/RW / WT/DS386/ RW, párrs. 7.644-7.716.

${ }^{57}$ Informes del Grupo Especial, Comunidades Europeas - Medidas que prohíben la importación y comercialización de productos derivados de focas ( $C E$ - Productos derivados de las focas»), WT/DS400/R / WT/DS401/R, párrs. 7.667-7.683. 
de los acuerdos OTC, ADPIC y GATT de $1994^{58}$, pero las reclamaciones sin infracción (que no se presentaron) se podrían haber basado también en las concesiones arancelarias de Australia para cigarros y cigarrillos. Sin embargo, las partes reclamantes habrían tenido que demostrar anulación o menoscabo de sus expectativas legítimas de acceso al mercado australiano en circunstancias cuando ninguno de ellos exportaba una cantidad importante de cigarros o cigarrillos a ese país durante la Ronda Uruguay o desde entonces ${ }^{59}$.

39. Simplemente, los Miembros no han elegido iniciar reclamaciones sin infracción en el ámbito de las concesiones arancelarias (o compromisos para servicios) en diferencias relativas a la propiedad intelectual ${ }^{60}$. La Decisión Ministerial nunca trató tales reclamaciones en esos ámbitos. Como se señaló, esta decisión, así como el art. 64.2 del ADPIC, solo se aplica respecto a obligaciones generales en el ámbito del ADPIC. Tampoco hay excepciones en el GATT 1994 o el AGCS que ampare las medidas de propiedad intelectual en general ${ }^{61}$.

40. En el caso de las reclamaciones por otra situación, los Miembros ni siquiera las inician en el mecanismo de solución de diferencias de la OMC; y a su vez todos los Miembros pueden vetar eventuales constataciones y conclusiones al respecto ${ }^{62}$. La Decisión Ministerial tiene un valor insignificante al respecto.

41. En consecuencia, las reclamaciones sin infracción y reclamaciones por otra situación se pueden iniciar en una diferencia relativa a la propiedad intelectual con la misma base que en cualquier otro tipo de diferencia relativa a la reglamentación nacional. Se podría decir lo mismo, ya sea que haya una Decisión que excluya la posibilidad de reclamaciones de esos tipos en el ámbito del ADPIC o que no haya ninguna Decisión Ministerial al respecto.

\subsection{Tratamiento en el ámbito del ADPIC mismo}

42. Si un Miembro iniciara una reclamación sin infracción en el ámbito del ADPIC, el grupo especial enfrentaría una cuestión preliminar importante antes de examinar el fondo de la reclamación.

\footnotetext{
${ }^{58}$ Las partes reclamantes no presentaron alegatos con respecto a sus reclamaciones bajo el art. III:4 del GATT de 1994 pero Cuba apoyó su reclamación bajo el art. IX:4 de ese acuerdo.

${ }^{59}$ Fuente: datos de COMTRADE sobre las importaciones australianas de las partes reclamantes en códigos de productos básicos 240210 y 240220 . Australia consolidó dos tarifas específicas y aplica tipos de cero.

${ }^{60}$ Una controversia relativa al comercio de servicios puede abarcar reclamaciones en el ámbito de los ADPIC y no solo el AGCS. Véase, por ejemplo, China - Medidas que afectan a los servicios de información financiera y a los proveedores extranjeros de información financiera (WT/DS372).

${ }^{61} \mathrm{El}$ art. XX(d) del GATT de 1994 solo se aplica a ciertas medidas para lograr la observancia con tal que las leyes y reglamentos principales relativos a la propiedad intelectual no sean incompatibles con las disposiciones del propio GATT de 1994. El art. XIV del AGCS ni siquiera contiene esa excepción. De todos modos, no hay disposición en los acuerdos de la OMC que excluya a priori reclamaciones sin infracción con respecto a la aplicación de medidas amparadas por una excepción general: véase el Informe del Órgano de Apelación, CE - Amianto, párrs. 188-191; cfr. TLCAN, anexo 2004, párr. 2.

62 ESD, art. 26.2.
} 


\subsubsection{Cuestión preliminar}

43. Un grupo especial podría iniciar su examen por la cuestión de saber si el art. 64 del ADPIC impide que un Miembro presente una reclamación sin infracción en el ámbito de este acuerdo y, de no ser el caso, si ese tipo de reclamación está disponible en el ámbito de las concesiones y compromisos individuales consolidados en el marco de otros acuerdos.

44. El art. 26.1 del ESD abarca las reclamaciones sin infracción cuando las disposiciones del párr. 1.b) del art. XXIII del GATT 1994 sean aplicables a un acuerdo abarcado. Estas disposiciones son aplicables al ADPIC en virtud de su art. 64.1, que dispone lo siguiente:

«Salvo disposición expresa en contrario en el presente Acuerdo, para las consultas y la solución de diferencias en el ámbito del mismo serán de aplicación las disposiciones de los arts. XXII y XXIII del GATT de 1994, desarrollados y aplicados por el Entendimiento sobre Solución de Diferencias».

45. Hubo «disposición expresa en contrario» en el ADPIC solo hasta finales de 1999, cuando el art. 64.2 venció, sin que se decidiera una prórroga sobre la base del art. 64.3. Desde entonces, de no haber un acuerdo contrario, un reclamante podría presentar una reclamación sin infracción en el marco del ADPIC en su petición de establecimiento de un grupo especial - aunque se supone que en realidad un Miembro solo tomaría ese paso después del vencimiento de la Decisión Ministerial- ${ }^{63}$. Sin embargo, esto no significa que tal reclamación pudiera llegar a ser exitosa en el ámbito de tal Acuerdo.

46. El objetivo del art. 64.1 es establecer el ADPIC como parte del mecanismo integrado de la solución de diferencias del ESD. Funciona conjuntamente con la definición de que el ADPIC es un «acuerdo abarcado» por el ESD. Esta definición se aplica también a los acuerdos sobre el comercio de mercancías del Anexo 1A del Acuerdo OMC — sin ponerse en duda si las reclamaciones sin infracción están disponibles en el ámbito de los mismos-. Ello se debe a que las reclamaciones sin infracción en diferencias en el ámbito de esos acuerdos se basan en concesiones arancelarias que figuran en las listas de cada Miembro.

47. El vínculo sustantivo entre el ADPIC y las concesiones arancelarias negociadas en el marco del GATT se recuerda en el considerando inicial del preámbulo del ADPIC en los siguientes términos: «Deseosos de reducir las distorsiones del comercio internacional y los obstáculos al mismo». Los proponentes que abogaron por el ADPIC explicaron de esta manera dicho vínculo:

«Algunos participantes hicieron también hincapié en que el valor de las concesiones comerciales negociadas en el GATT podía verse, y se veía ya, menos-

${ }_{63} \mathrm{El}$ art. 64.3 del ADPIC no especifica las consecuencias de no lograr recomendaciones sobre el alcance y las modalidades de esos tipos de reclamaciones en el ámbito de los ADPIC: CoRREA, C. M., op. cit., nota 34, p. 490. Sin embargo, no sería necesario ya que las mismas consecuencias derivan de la aplicación del art. 64.1. 
cabado por la protección inadecuada o excesiva de los derechos de propiedad intelectual» ${ }^{64}$.

48. Esta fue la justificación dada para agregar la propiedad intelectual a una Ronda de negociaciones bajo los auspicios del GATT y quedó tal cual en el texto final del ADPIC. Si las expectativas de los proponentes de este Acuerdo con respecto al acceso a los mercados de productos protegidos mediante propiedad intelectual no fueran satisfechas luego de la implementación de sus obligaciones, la base legal correcta para reclamar anulación o menoscabo sin infracción seguirían siendo las concesiones comerciales negociadas en el ámbito del GATT de 1994. El ADPIC no cambió esa base.

49. Esta lectura se ve corroborada por las normas mínimas de la segunda parte del ADPIC que prevén derechos exclusivos de impedir que terceros exploten materia protegida mientras los derechos positivos de explotar la materia derivan de otros leyes y reglamentos ${ }^{65}$, una distinción que se ve reflejada en los principios enumerados en el art. 8 del mismo acuerdo. Además, el origen y el objetivo de las reclamaciones sin infracción tales como se explicaron en el informe del Grupo Especial del GATT en CEE - Oleaginosas I, y el informe del Órgano de Apelación en $C E$ - Amianto, confirman que las reclamaciones sin infracción no estarían disponibles en el ámbito de obligaciones generales ${ }^{66}$.

50. En consecuencia, un grupo especial puede constatar previamente que una reclamación sin infracción iniciada en el ámbito del ADPIC mismo no da derecho a ninguna reclamación válida.

\subsubsection{Examen de fondo}

51. Si un grupo especial intentara llevar a cabo un examen de fondo de una reclamación sin infracción basada en las obligaciones del ADPIC, aunque fuera de forma arguendo, el reclamante se enfrentaría a obstáculos muy importantes. Además, una eventual decisión del grupo especial de examinar una reclamación sin infracción basada en una obligación podría ser revocada en apelación.

52. Los obstáculos para el reclamante derivan de los requisitos del ESD, de las disposiciones del ADPIC y de la jurisprudencia del GATT/OMC. El art. 26.1 del ESD prescribe que el reclamante presente una «justificación de-

${ }^{64}$ Reunión del grupo de negociaciones sobre los aspectos de los derechos de propiedad intelectual relacionados con el comercio, incluso el comercio de mercancías falsificadas, del 23 de septiembre de 1987, Nota de la Secretaría, MTN.GNG/NG11/3, párr. 8. Véase también la declaración hecha por los Estados Unidos en la reunión del 25 de marzo de 1987 con respecto al valor de las concesiones negociadas en anteriores rondas de negociaciones comerciales, MTN.GNG/NG11/W/2, pp. 1-2.

65 Por ejemplo, leyes de censura y aprobaciones de comercialización de fármacos. Véase Aввотт, F. M., «WTO Dispute Settlement and the Agreement on Trade-Related Aspects of Intellectual Property Rights», en Petersmann, E.-U. (ed.), op. cit., nota 7, pp. 413-437, esp. pp. 433-434.

66 Véase supra nota 8. 
tallada» sin gozar de una presunción de anulación o menoscabo. El art. 8 del ADPIC ampara a priori varias clases de medidas de este tipo de reclamación porque autoriza de manera explícita que los Miembros adopten ciertas medidas siempre que esas medidas sean compatibles con lo dispuesto en el Acuerdo (que es típicamente el caso de las medidas en litigio en una reclamación sin infracción). Respecto a medidas no abarcadas por el art. 8, la jurisprudencia del GATT/OMC suele exigir un grado extraordinario de menoscabo de una ventaja y pruebas contundentes de expectativas legítimas de tal ventaja ${ }^{67}$.

53. Por ejemplo, en Australia - Empaquetado genérico de tabaco, las partes reclamantes podrían haber alegado, como alternativa a sus reclamaciones de infracciones, que los estándares mínimos del ADPIC relativos a las marcas de fábrica o de comercio, así como sus disposiciones relativas al ejercicio de los derechos de propiedad intelectual, crearon expectativas legítimas que los titulares podrían utilizar sus marcas de formas diversas. Habrían llevado la carga de la prueba de que las medidas australianas no eran «necesarias para proteger la salud pública» dentro de los términos del art. 8.1 del ADPIC y que no se podrían haber anticipado de otra manera. Los reclamantes habrían tenido que demostrar que, durante las negociaciones sobre el ADPIC, cabía legítimamente esperar que Australia no adoptaría sus medidas relativas al uso de las marcas en el empaquetado de productos de tabaco, ni siquiera más de veinte años después. La evaluación del grado de menoscabo de la ventaja de las obligaciones habría sido muy amplia porque los estándares mínimos de protección de las marcas se aplican a signos para todo tipo de mercancías y servicios. Dado que las medidas australianas se aplican solamente a los productos de tabaco, habría sido muy difícil comprobar un nivel de menoscabo suficiente.

54. La aplicación del ESD no implica la disponibilidad de reclamaciones sin infracción en el ámbito del ADPIC. El texto de este último acuerdo, el contexto de las listas de concesiones de los Miembros y la naturaleza integrada del mecanismo de solución de diferencias en la OMC, indican que un grupo especial puede constatar que una reclamación sin infracción iniciada en el ámbito del ADPIC mismo no da derecho a ninguna reclamación válida. Si un grupo especial intentara llevar a cabo un examen de fondo de una reclamación sin infracción basada en las obligaciones del ADPIC, la parte reclamante se enfrentaría a múltiples dificultades.

\section{CONCLUSIÓN}

55. El debate sobre las reclamaciones sin infracción y las reclamaciones por otra situación en el ámbito del ADPIC deriva de la ubicación de este

${ }^{67}$ El raciocinio era más amplio en el informe del Grupo Especial en Japón - Películas (WT/DS44/R) pero no afectó al resultado debido a los hechos del asunto. Véase Аввотт, F. M., «TRIPS in Seattle: The Not-So-Surprising Failure and the Future of the TRIPS Agenda», Berkeley Journal of International Law, vol. 18, 2000, pp. 165-179, esp. pp. 175-178. 
acuerdo y el GATT en anexos separados del Acuerdo OMC. A la luz de la jurisprudencia, queda claro ahora que el ADPIC se aplica de manera acumulativa con el GATT de 1994 y los demás acuerdos de esta organización. Esto implica que las reclamaciones sin infracción han estado disponibles desde siempre en diferencias relativas a la propiedad intelectual, tal como en otras controversias de la OMC relacionadas con la reglamentación nacional. Esas reclamaciones deben presentarse basadas en las concesiones o compromisos individuales que abarcan las mercancías o servicios pertinentes. De la misma manera, esas reclamaciones siguen siendo una acción excepcional.

56. Si un Miembro presentara una reclamación sin infracción en el ámbito del ADPIC mismo, el grupo especial debería constatar que ese tipo de reclamación no da derecho a ninguna reclamación válida, tomando en cuenta el texto de este acuerdo, que contiene solamente obligaciones generales, el contexto de otros acuerdos de la OMC, que incluyen listas de concesiones y compromisos individuales, y la naturaleza integrada del mecanismo de solución de diferencias de la OMC. Por otro lado, las reclamaciones por otra situación son inauditas desde el establecimiento de esta organización.

57. Por ende, el debate sobre las reclamaciones sin infracción y las reclamaciones por otra situación en el Consejo de los ADPIC debería terminar. Las Decisiones Ministeriales podrían ser contraproducentes porque alentarían a las partes a hacer inferencias a contrario que esas reclamaciones, de ser presentadas, podrían ser válidas en el ámbito del ADPIC mismo.

\section{RESUMEN}

\section{LAS RECLAMACIONES SIN INFRACCIÓN EN LAS DIFERENCIAS RELATIVAS A LA PROPIEDAD INTELECTUAL EN LA OMC}

Los Miembros de la OMC han acordado en sucesivas oportunidades no presentar reclamaciones sin infracción en el ámbito del Acuerdo sobre los ADPIC. La decisión más reciente en tal sentido se tomó durante la XI Conferencia Ministerial de Buenos Aires en diciembre de 2017. La controversia sobre Australia - Empaquetado genérico de tabaco es precisamente el tipo de caso donde esa decisión podría llegar a tener aplicación para evitar tales reclamaciones. Aun así, nada hubiera impedido a las partes reclamantes presentar reclamaciones sin infracción en el ámbito de las concesiones arancelarias de Australia para cigarros y cigarrillos. A partir de este ejemplo, se explora el alcance de esas reclamaciones, tal como surge de la relación entre el GATT de 1994 y el ADPIC. Se llega a la conclusión de que las reclamaciones sin infracción han estado disponibles desde siempre en las diferencias relativas a la propiedad intelectual cuando se presentan en el ámbito de concesiones o compromisos individuales; por más que fuera difícil justificarlas. Por otro lado, si un Miembro presentara una reclamación sin infracción en el ámbito del ADPIC mismo, luego del vencimiento de la Decisión Ministerial, un grupo especial podría constatar que ese tipo de reclamación no constituye de todas maneras una vía de acción válida.

Palabras clave: propiedad intelectual, ADPIC, Derecho internacional económico, OMC, solución de diferencias, reclamaciones sin infracción. 


\section{ABSTRACT \\ NON-VIOLATION COMPLAINTS IN INTELLECTUAL PROPERTY DISPUTES IN THE WTO}

WTO Members have agreed many times not to file non-violation and situation complaints under the TRIPS Agreement, most recently in a Ministerial Decision adopted in Buenos Aires in December 2017. The ongoing dispute in Australia - Tobacco Plain Packaging is just the type of case where that Decision is intended to avoid non-violation claims. Even so, nothing prevented the complainants in that case from filing non-violation claims under Australia's tariff concessions on cigars and cigarettes. Drawing on that example, this article explores the scope for non-violation claims in intellectual property disputes as it emerges from the relationship between GATT 1994 and TRIPS. It concludes that nonviolation claims have always been available in intellectual property disputes when filed under WTO Members' individual concessions and commitments, although they would be difficult to prove. However, if a Member presented such a claim under TRIPS itself after the expiry of the current Ministerial Decision, a panel could find that it disclosed no valid cause of action.

Keywords: intellectual property, TRIPS, international economic law, WTO, dispute settlement, non-violation. 